\title{
PERCEPÇÃO DE CLIENTES EM RELAÇÃO ÀS NORMAS DE BIOSSEGURANÇA UTILIZADAS NOS CENTROS DE EMBELEZAMENTO E ESTÉTICA
}

\section{PERCEPTION OF CUSTOMERS IN RELATION TO THE BIOSECURITY USED IN THE BEAUTY AND AESTHETICS CENTERS}

\author{
Susanne Rafaelle Dutra França ${ }^{1}$; Ellen Andressa Alencar ${ }^{2}$; Solange Almeida Bacelar ${ }^{3}$, Ludmila \\ Rodrigues L. N. ${ }^{4}$, Ana Lourdes Avelar Nascimento ${ }^{5}$; \\ Patrícia Rodrigues Ferreira ${ }^{6}$; Sarah Tarcisia Rebelo Ferreira de Carvalho ${ }^{7}$
}

RESUMO: A adequada prática da biossegurança garante a integridade física dos profissionais de estabelecimentos e de seus clientes. Neste contexto, esta pesquisa objetivou analisar a percepção de clientes em relação às normas de biossegurança utilizadas nos centros de embelezamento e estética. Realizou-se um estudo de caráter observacional, descritivo e transversal, com 48 clientes de centros de embelezamento e estética de São Luís-MA. Para a coleta de dados, utilizou-se questionário de Souza, Marchi e Bettega (2007) sobre normas de biossegurança, incluindo: uso de equipamentos de proteção, estrutura dos estabelecimentos, limpeza e sanitização do ambiente, gerenciamento de resíduos sólidos, assepsia, desinfecção e esterilização dos artigos. Constatou-se que 58\% dos clientes observaram uso de máscaras pelos profissionais, 52,08\% de jalecos, 75\% de luvas, 58,33\% não observaram existência de extintores e $85,42 \%$ de kits de primeiros socorros. Em relação à estrutura, 95\% afirmaram que o local é ventilado, 97\% que é iluminado e 48\% que o local para a preparação de químicas é apropriado. Quanto à limpeza, 100\% observaram limpeza do chão, $89,58 \%$ a limpeza de banheiros e $81,25 \%$ limpeza dos mobiliários em geral. Sobre o gerenciamento de resíduos, $60 \%$ não observaram separação do lixo e 33\% observaram a existência de local adequado para armazenamento do lixo. 50\% dos entrevistados indicaram uso de materiais descartáveis, e $22 \%$ a esterilização dos artigos antes dos procedimentos. $72,92 \%$ observaram a

\footnotetext{
${ }^{1}$ Egressa do Curso de Estética da Universidade Ceuma. E-mail: Junynho2004@ hotmail.com

${ }^{2}$ Discente do Curso de Estética da Universidade Ceuma. E-mail: ellenmakes@ outlook.com

${ }^{3}$ Docente do Curso de Estética da Universidade Ceuma. E-mail: solange.bacelar@ceuma.br

${ }^{4}$ Docente do Curso de Estética da Universidade Ceuma. E-mail:ludpenha@gmail.com

${ }^{5}$ Docente da Universidade Ceuma. E-mail: analouavelar@ hotmail.com

${ }^{6}$ Docente do Curso de Estética da Universidade Ceuma. E-mail: patriciarf80@ig.com.br

${ }^{7}$ Docente do Curso de Fisioterapia da Universidade Ceuma. E-mail: sarahtrfc@ hotmail.com
} 
higienização das mãos dos profissionais. Desta forma, considera-se que o profissional de estética deve implantar e seguir as condutas de biossegurança em seu estabelecimento, esclarecendo-as aos seus clientes.

PALAVRAS-CHAVE: Equipamentos de proteção individual; Equipamentos de proteção coletiva; Centros de embelezamento e estética.

\begin{abstract}
The proper use of protective equipment by aesthetic professionals works as protective barriers that reduce the risk of cross-contamination. This research aimed to analyze the perception of customers regarding the use of personal protective equipment (EPI's) and collective (EPC's) by hairdressers of beautification centers and esthetics of São Luís. For this, a research was carried out observational, descriptive and carried out with 48 clients of beautification and aesthetics centers in São Luís-MA. For the data collection, a questionnaire was used by Souza, Marchi and Bettega (2007) on biosafety standards. Regarding the use of Protective Equipment in the establishments studied, $58 \%$ of clients stated that they observed the use of masks by professionals, $52.08 \%$ of coats, $75 \%$ of gloves, $43.75 \%$ of cap and $20.83 \%$ of glasses of protection. Regarding the collective protection equipment, $58.33 \%$ reported not observing the existence of extinguishers and $85.42 \%$ of first aid kits. Thus, it was concluded that the majority of clients demonstrated aspects related to the use of PPE's as a mask and gloves, but there was a low observation regarding the use of EPC's and some PPE's such as a cap, lab coat and goggles. In this way, it is necessary that the use of protective equipment in these centers becomes a daily habit.
\end{abstract}

KEYWORDS: Individual protection equipment; Collective protection equipment; Beautification and aesthetics centers 


\section{Introdução}

A biossegurança, segundo a definição etimológica da palavra, refere-se a segurança da vida ou vida segura, sendo compreendida então, como um conjunto de medidas que busca prevenir, minimizar ou eliminar riscos inerentes às atividades de pesquisa, produção, ensino, desenvolvimento tecnológico e prestação de serviços, que possam comprometer a integridade e saúde do homem, dos animais, do meio ambiente e a qualidade dos serviços desenvolvidos. Ou seja, a principal preocupação da biossegurança, é manter a proteção no inter-relacionamento entre o homem e a natureza (animais e meio ambiente), considerando que qualquer alteração nesse relacionamento pode gerar um desequilíbrio e provocar danos entre os mesmos (ARDIONS; NAVARRO; CARDOSO, 2013).

No segmento da beleza e estética, pode-se dizer que a biossegurança está relacionada às boas práticas destes profissionais, de modo a garantir a sua integridade e de seus clientes, pois ambos estão expostos a uma série de riscos que podem ser físicos (que incluem ruídos, calor, vibrações, pressões anormais e radiações); químicos (que compreendem exposição às substâncias, compostos ou produtos que podem entrar em contato com o organismo por via respiratória, ingestão ou contato com a pele); os biológicos (que incluem bactérias, vírus, fungos, protozoários, parasitas ou substâncias e objetos contaminados por microrganismos.); os ergonômicos; e acidentes, que consideram os riscos citados, associados às instalações físicas do estabelecimento (GARBACCIO, 2013).

Dentre os riscos inerentes aos procedimentos que envolvem essas atividades, o risco biológico representa maior ameaça à saúde e integridade do cliente, tendo em vista que durante os procedimentos estéticos e de embelezamento, áreas do corpo são manipuladas por instrumentos, como pinças, pincéis, alicates, palitos, lâminas, espátulas, algodão, tesouras, agulhas, entre outros instrumentos que podem gerar contaminação e disseminação de doenças infecciosas, como HIV/AIDS, Hepatites B e C e infecções bacterianas e fúngicas (SOBRINHO et al., 2014).

Garbaccio e Oliveira (2012), indicam que essas contaminações podem acontecer de forma direta quando a transmissão biológica ocorre sem intermediação de vetores, e de forma indireta, quando a contaminação ocorre através de contato com vetores, como material ou instrumento contaminado quando não adotadas as medidas corretas de segurança. De acordo com Mello (2011) para prevenir, reduzir ou eliminar esse risco e os demais, deve-se adotar boas condutas de biossegurança, que incluem uma série de cuidados como a limpeza do estabelecimento e mobiliário, desinfecção e assepsia de utensílios, a esterilização de artigos, principalmente os perfurocortantes 
que transmitem um risco maior de contaminação, a utilização de materiais descartáveis , assim como a higienização e assepsia das mãos dos profissionais, visto que esta é um dos principais instrumentos utilizados nos centros de embelezamento e estética.

Para Carvalho et al. (2009) e Garcia, Moser e Bettega (2007), os clientes devem também exigir o uso dos equipamentos de proteção individual (EPI’s), que consiste em todo dispositivo ou produto de proteção individual do profissional, que impede que microrganismos e produtos químicos possam contaminar o cliente e o profissional. Assim como também se deve observar a utilização correta de equipamentos de proteção coletiva (EPC’s), que são todos os utensílios voltados para a proteção do grupo, como extintores de incêndio para produtos químicos, elétricos e papéis, visando uma possível emergência.

Conforme Garcia e Ramos (2004), a preocupação com descarte de resíduos gerados em centros de embelezamento e estética também faz parte das condutas de biossegurança, devendo haver um cuidado com o destino dado ao lixo para evitar a contaminação, visando promover a proteção dos trabalhadores, a prevenção da saúde pública, dos recursos naturais e do meio ambiente, seguindo para isso um regulamento de gerenciamento de resíduos, que engloba desde o acondicionamento ao transporte externo do lixo gerado nos estabelecimentos.

Diante dessas informações observa-se a importância da abordagem e conhecimento da boa conduta de biossegurança, tendo em vista que pesquisas relacionadas à utilização da mesma em serviços de embelezamento e estética ainda são escassas; e que a frequente procura por esses serviços vem movimentando e impulsionando o desenvolvimento da área de Estética e Cosmetologia, especificamente aumentando o número de salões, clínicas estéticas, spas e estabelecimentos afins, instigando a necessidade de um olhar mais atencioso e crítico no que se refere à qualidade e segurança nos serviços prestados (SOUZA; MARCHI; BETTEGA, 2007). Sendo assim, essa pesquisa objetiva analisar a percepção de clientes em relação às normas de biossegurança utilizadas nos centros de embelezamento e estética de São Luís-MA.

\section{Materiais e métodos}

Tratou-se de uma pesquisa observacional, quantitativa, descritiva e transversal com clientes frequentadores de centros de embelezamento e estética no município de São Luís, conduzida no período entre os meses de abril e junho de 2017. Foram selecionados quatro clientes de cada um dos 12 estabelecimentos visitados, situados em diferentes bairros, todos devidamente cadastrados em órgãos públicos como prefeitura e ANVISA, perfazendo um total amostral de 48 
clientes. O critério de participação no estudo incluiu os quatro primeiros clientes com idade maior ou igual a 18 anos, independente de gênero que mostraram disponibilidade e interesse em participar da pesquisa.

A coleta de dados foi realizada mediante a aplicação de um questionário estruturado e autoaplicável de Sousa, Marchi e Bettega (2007), composto por 16 questões sobre diversos tópicos de biossegurança em Estética e Cosmetologia, que considerava as seguintes variáveis: IPreocupação do consumidor dos serviços de beleza em relação às normas de Biossegurança; IIAnálise estrutural do estabelecimento; III Limpeza e sanitização do ambiente; IV- Assepsia, desinfecção e esterilização de artigos; V- Utilização de EPI's e EPC's; e VI- Gerenciamento de resíduos (Anexo 1).

Para a análise dos dados foi utilizado a estatística descritiva, através da análise das medidas de tendência central, e de dispersão e distribuição de frequências absolutas e percentuais para as variáveis estudadas. Os dados foram digitados e analisados mediante o programa Excel,

Esta pesquisa foi realizada baseada na resolução 466/2012 do Conselho Nacional de Saúde (CNS) que regulamenta as pesquisas envolvendo seres humanos. Os participantes foram devidamente informados e esclarecidos quanto à importância e objetivo da pesquisa e após o aceite, assinaram o Termos de Consentimento Livre e Esclarecido.

\section{Resultados e Discussão}

Quanto ao uso de Equipamentos de Proteção pelos profissionais dos estabelecimentos estudados, os clientes afirmaram observar principalmente o uso de luvas (75\%), máscaras pelos $(64,58 \%)$, de jalecos $(52,08 \%)$. Sobre os equipamentos de proteção coletiva, 58,33\% relataram não observar a existência de extintores e $85,42 \%$ de kits de primeiros socorros (Tabela 1).

Tabela 1- Equipamentos de proteção utilizados nos centros de embelezamento e estética.

\begin{tabular}{lcc}
\hline \multicolumn{1}{c}{ Equipamentos de Proteção } & N & \% \\
\hline Máscara & 31 & 64,58 \\
Sim & 17 & 35,42 \\
Não & & \\
Jaleco & 25 & 52,08 \\
Sim & 23 & 47,92 \\
Não & & \\
Luvas & 36 & 75 \\
Sim & &
\end{tabular}




\begin{tabular}{lcc} 
Não & 12 & 25 \\
Gorro & & \\
Sim & 21 & 43,75 \\
Não & 27 & 56,25 \\
Óculos de proteção & & \\
Sim & 10 & 20,83 \\
Não & 38 & 79,17 \\
Extintores de incêndio & & \\
Sim & 20 & 41,67 \\
Não & 28 & 58,33 \\
Kits de primeiros socorros & & \\
Sim & 07 & 14,58 \\
Não & 41 & 85,42 \\
\hline
\end{tabular}

$\mathrm{Na}$ avaliação acerca desta conduta de segurança, percebeu-se baixa observação quanto ao uso de óculos de proteção; gorros e jalecos. Estudo realizado por Fernandes e Sousa (2016) observou resultado semelhante. A falta de observação dos clientes em relação ao uso desses EPI's pode ser resultante do não conhecimento dos profissionais de estética quanto à função desses itens.

Segundo Eufrásio, Santos e Novotny (2011), além de funcionar como barreiras de proteção o uso de óculos de proteção, gorros e jalecos reduzem o risco de contaminação cruzada, devendo ser trocados sempre que necessário.

Em relação ao uso de máscaras e luvas, itens também indispensáveis de proteção, o percentual de observação mostrou-se maior. O uso de máscaras foi observado por 79,12\% e o de luvas por $75 \%$, resultado consonante com o de Fernandes e Sousa (2016) em que 82\% identificaram o uso de máscaras e $85 \%$ o uso de luvas pelos profissionais.

Embora esses resultados tenham revelado um percentual alto, faz-se necessário incentivar a o uso diário desses dispositivos, visto que o uso de máscaras protege as vias respiratórias evitando que gotículas de saliva ou secreção entrem em contato com o cliente e vice-versa. As luvas também configuram medidas de proteção para o cliente e o profissional, devendo ser usadas sempre que houver possibilidade de contato com sangue, secreções, mucosas e tecidos, e devem ser trocadas após cada atendimento (CARDOSO et al., 2014).

Nesta pesquisa, destacou-se ainda a baixa observação de clientes em relação à existência de extintores de incêndio e kits de primeiros socorros nos estabelecimentos, resultados semelhantes ao encontrado em Santa Catarina, por Souza, Marchi e Bettega (2007), em que apenas 50\% 
referiram observar a presença de extintores de incêndio no estabelecimento frequentado, e somente $34 \%$ afirmaram observar a existência de kits de primeiros socorros.

Apesar de serem obrigatórios, estes itens ainda são pouco observados pelos clientes, provavelmente devido a uma ineficaz fiscalização dos órgãos responsáveis para que exijam a disponibilização de equipamentos de proteção coletiva nos estabelecimentos.

O estabelecimento deve dispor extintores adequados para cada tipo de produto, posicionados em locais visíveis e acessíveis, sinalizados e com carga válida. Os kits de primeiros socorros também devem ser disponibilizados pelo estabelecimento e conter material necessário para atender possíveis emergências recorrentes de procedimentos realizados.

$\mathrm{Na}$ descrição sobre estrutura dos estabelecimentos, 95\% dos participantes afirmaram observar que o local é ventilado e $97 \%$ afirmaram que o local é bem iluminado e $48 \%$ indicaram que o local para a preparação de químicas é apropriado. Sobre a limpeza do estabelecimento, 100\% relataram observar a limpeza do chão, 89,58\% a limpeza de banheiros e 81,25\% relataram observar a limpeza dos mobiliários em geral (Tabela 2).

Tabela 2 - Percepção de clientes quanto à estrutura e limpeza de centros de embelezamento e estética.

\begin{tabular}{llc}
\hline Estrutura e Limpeza do Estabelecimento & N & \% \\
\hline Ventilação & & \\
Sim & 44 & 91,67 \\
Não & 04 & 08,33 \\
Iluminação & & \\
Sim & 46 & 95,83 \\
Não & 02 & 04,17 \\
Local separado para a preparação de químicas & & \\
Sim & 23 & 48 \\
Não & 25 & 52 \\
Limpeza de chão & & \\
Sim & 48 & 100 \\
Não & 00 & 00 \\
Limpeza de banheiros & & \\
Sim & 43 & 89,58 \\
Não & 05 & 10,42 \\
Limpeza de mobiliário em geral & & \\
Sim & 39 & 81,25 \\
Não & 09 & 18,75 \\
\hline
\end{tabular}


A percepção dos clientes evidenciada neste estudo está em concordância com a pesquisa realizada em Balneário Camboriú por Garcia, Moser e Bettega (2007) no quesito estrutura do estabelecimento, em que $95 \%$ dos participantes relataram observar que o local é ventilado e $97 \%$ que o local é iluminado. Quanto ao local apropriado para a preparação de químicas, observou-se uma diferença entre os percentuais das duas pesquisas, já que a realizada em Camboriú apontou que $85 \%$ observaram a existência desse local. O resultado obtido em São Luís sobre esse item pode decorrer da falta de espaço nos estabelecimentos.

Pinto, Abreu e Gallas (2008) ressaltam que em qualquer estabelecimento de beleza e estética deve haver uma estrutura adequada para as atividades ali desenvolvidas, de forma a garantir a segurança e saúde de clientes e profissionais. O estabelecimento deve dispor de iluminação e ventilação natural ou artificial de forma a proporcionar adequadas condições de segurança e conforto, sendo recomendável um bom grau de claridade e ventilação no ambiente. Um espaço reservado para a preparação de químicas seria o ideal para evitar a inalação pelo cliente dos fortes gases liberados durante esse processo.

Com relação à limpeza e sanitização do ambiente, item imprescindível aos estabelecimentos de beleza e estética, os resultados mostraram-se satisfatórios e consoantes com os obtidos por Souza, Marchi e Bettega (2007), que apontou que 99\% dos clientes descreveram como positiva a limpeza do chão, $96 \%$ afirmaram observar a limpeza de banheiros e $93 \%$ observaram de forma positiva a limpeza dos mobiliários em geral. Esses dados evidenciaram que o público-alvo estava atento a essas questões, provavelmente por considerarem esses itens como questões de higiene que influenciam na escolha do estabelecimento a ser frequentado.

Neste sentido, todos os estabelecimentos devem possuir em suas dependências pisos e paredes laváveis, instalações e mobiliários conservados e asseados. A limpeza deve ser diária e sempre que se fizer necessária, através do uso de detergentes (sabão) para eliminar as sujidades. A desinfecção por sua vez, deve acontecer sempre que a superfície entrar em contato com material que ofereça maiores riscos de contaminação. Para esse procedimento é recomendado o uso de um agente químico saneante que elimine 99,9\% dos agentes contaminantes presentes na área, como os compostos clorados (como o hipoclorito de sódio) e o álcool etílico (etanol) (ZANCHETTA; POZZEBOM; RAMOS, 2008). Assim, a limpeza e desinfecção do estabelecimento feita de forma correta e com os produtos adequados são de grande valia para manter as condutas de biossegurança.

Sobre o quesito gerenciamento de resíduos nos centros de embelezamento e estética, dos sujeitos participantes da pesquisa $60 \%$ afirmaram não observar se no estabelecimento há separação 
do lixo e apenas 33\% afirmaram observar a existência de um local adequado para a identificação e armazenamento do lixo (Gráfico 1).

Gráfico 1 - Percepção de clientes quanto ao gerenciamento de resíduos sólidos em centros de embelezamento e estética. São Luís- MA, 2017.

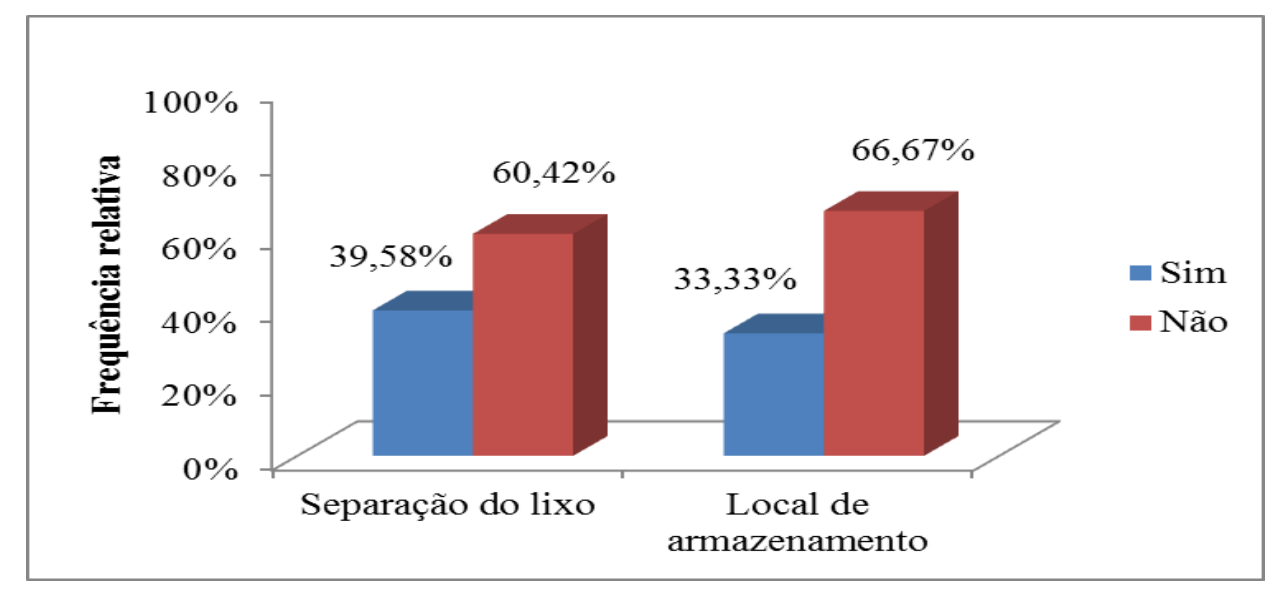

Os clientes dos serviços de beleza e estética indicaram descaso dos estabeleciemntos analisados quanto ao lixo gerado nos mesmos. Este resultado tambem foi evidenciado no estudo de Souza, Marchi e Bettega (2007), em que apenas 30\% dos clientes observaram a separação e a existência de um local adequado para a identificação e armazenamento dos resíduos. Considera-se este fato relevante, pois o cuidado com o descarte dos resíduos gerados nos estabelecimentos de beleza também fazem parte das condutas de biossegurança.

De acordo com Mello (2011), existe um regulamento técnico para o gerenciamento de resíduos de serviços de saúde que também devem ser seguidos por outros estabelecimentos que levem risco à saúde das essoas, que compreende etapas intra e extra estabelecimento, como segregação, acondicionamento, transporte e destino final (tratamento do resíduo), visando à proteção do homem e do meio ambiente. Para Costa e Fonseca (2009), os resíduos devem ser separados no momento e no local de sua geração, e acondicionados logo em seguida, em saco de lixo normal e impermeável, quando estes forem comuns; em sacos constituídos de material impermeável, resistente à ruptura, à punctura e vazamento, quando se tratar de resíduos químicos ou biológicos, contendo a identificação com símbolo e a inscrição do tipo de resíduo; e em caso de resíduo perfuro cortante, devem ser acondicionados em recipientes constituídos de material rígido e resistente, e sua identificação deve conter o símbolo internacional de risco biológico, acrescido da inscrição perfuro cortante. 
A etapa do armazenamento constitui-se na guarda temporária dos resíduos já acondicionados até à apresentação para a coleta externa. Ainda nessa etapa, os resíduos devem ser armazenados em recipientes e não sobre os pisos, e devem estar localizados próximo ao local de geração. $\mathrm{O}$ transporte interno por sua vez, constitui-se da etapa em que os resíduos são levados de dentro do estabelecimento para o ponto de coleta externa (WARMELING; MOREIRA; BETTEGA, 2008). Segundo Lovo (2011), os resíduos recicláveis devem ser recolhidos por coleta seletiva, e os infectantes (biológicos, químicos e perfuro cortantes) por coleta especial, geralmente através do pagamento a empresas especializadas. Por fim, devem ser direcionados ao seu destino final que é a última etapa do gerenciamento de resíduos.

Este estudo analisou também aspevtos como relacionados à assepsia, desinfecção e esterilização de artigos, assim como o uso de materiais descartáveis. Sobre estes itens, 50\% dos entrevistados afirmaram observar que todos os materiais usados pelo profissional durante os procedimentos são descartáveis, e apenas $22 \%$ relataram observar a esterilização dos artigos antes dos procedimentos. Quanto a higienização das mãos do profissionais, 72,92\% relatarm observar essa prática ( Gráfico 2).

Gráfico 2- Percepção de clientes em relação a esterilização, uso de artigos descartáveis e higienização das mãos dos profissionais de centros de embelezamento e estética. São Luis- MA, 2017.

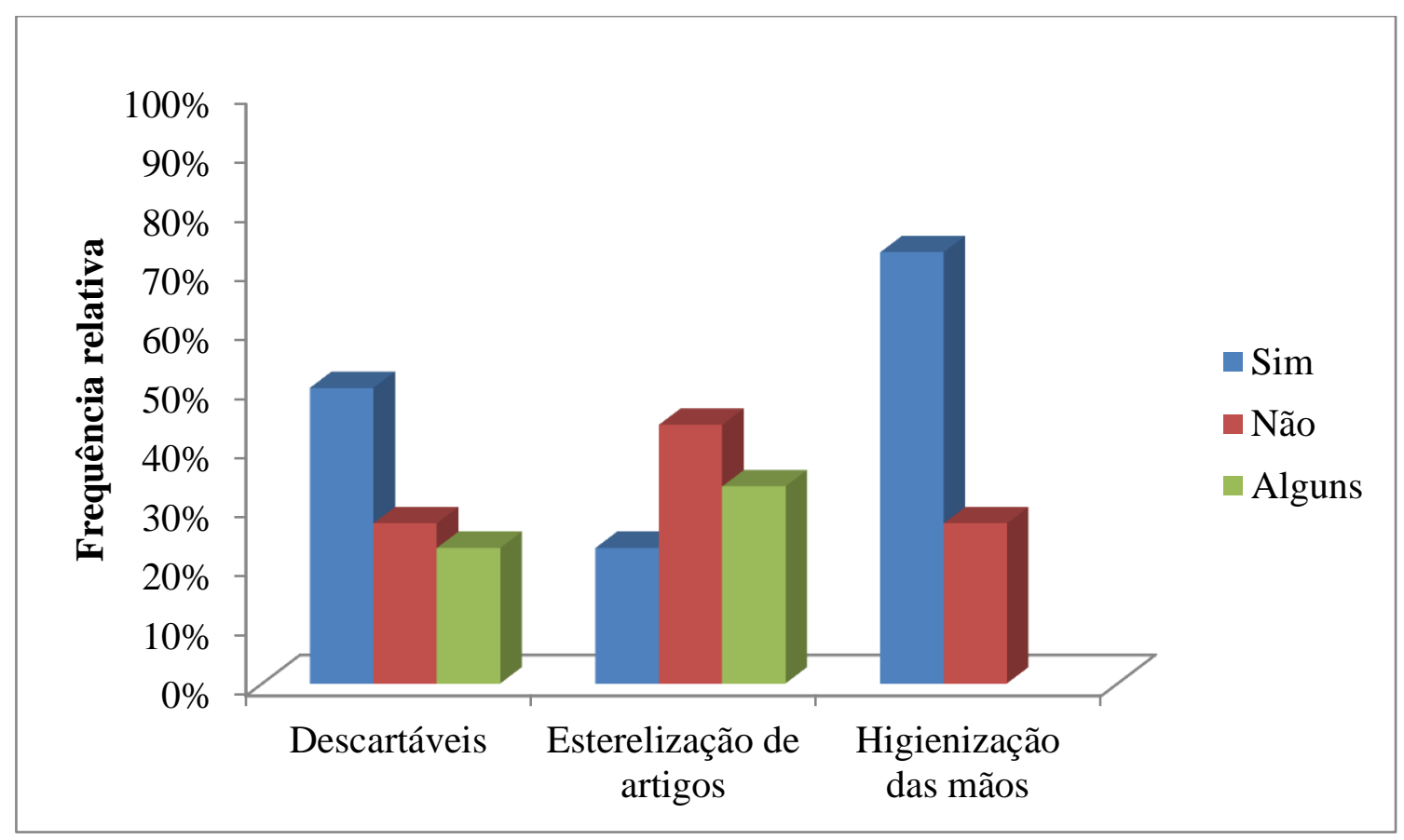


Estes resultados corroboram com os do estudo realizado por Vieira (2013), em que somente 39,5\% dos clientes afirmaram observar a esterilização dos artigos, e 79\% revelaram não observar se os materiais utilizados eram ou não descartáveis, o que evidencia resultados insatisfatórios em relação a essa conduta de biossegurança. Esse resultado pode ser proveniente da falta de informação sobre os riscos aos quais estão expostos quando não seguidas essas condutas, ou ainda por sentirem-se constrangidos ao exigirem do profissional e do estabelecimento artigos descartáveis e esterilizados durante o atendimento, ou por infelizmente o estabelecimento frequentado não dispor de equipamentos de esterilização e kits individuais descartáveis.

Segundo Queiroz e Mejia (2015), existe nos centros de embelezamento e estética o risco de contaminação por vírus, fungos e bactérias, e que a maioria dos artigos utilizados nos procedimentos podem atuar como vetores causando infecções cruzadas, como micoses, causada por fungos e pode ser transmitida através de objetos contaminados; hepatites B e C, causada por diferentes tipos de vírus e que em estabelecimentos de beleza, podem ocorrer através de contato direto com sangue (compartilhamento de objetos de higiene pessoal, alicates, lâminas, agulhas, entre outros); AIDS, que pode ser transmitida através de objetos perfuro cortante e por contato direto com determinados fluídos corporais; entre outros tipos de infecção.

Conforme Garcia, Bento e Costa (2012), para a segurança dos clientes e profissionais, os artigos perfuro cortantes devem passar por processo de limpeza com detergente, água e ação mecânica para diminuir a quantidade de microrganismos existentes e em seguida, devem passar pelo processo de esterilização, que se refere à completa eliminação de patógenos, através do calor seco (estufa ou forno de Pasteur) ou calor úmido (autoclave). Os outros artigos, como pentes, escovas, entre outros, devem ser submetidos ao processo de higienização e assepsia através de produtos específicos.

Em relação à higienização das mãos dos profissionais, embora este estudo aponte que 72,92\% dos participantes observaram esse critério, o percentual de não observância ainda é alto. Dados semelhantes ao encontrado por Fernandes e Sousa (2016), em que o percentual de observância foi de $64,23 \%$. Sugere-se que esse resultado pode decorrer do descuido do profissional em não realizar essa prática e do cliente por sua vez, de não exigir.

A higienização das mãos pelo profissional é um processo simples e econômico, que previne a propagação de contaminação cruzada, deve acontecer antes e depois dos atendimentos, mesmo que este faça uso de luvas, visto que as mãos são um dos principais instrumentos utilizados nos atendimentos desenvolvidos nos centros de embelezamento e estética (KUHN; RENE, 2012). 
Para favorecer a prática de higienização, Garbaccio e Oliveira (2012) recomenda o uso de sabão e água, aliados à fricção para remover os microrganismos, e papel toalha para a secagem das mãos.

\section{Conclusão}

A maioria dos clientes demonstrou observar aspectos relacionados à ventilação, iluminação, limpeza do ambiente, higienização das mãos do profissional e do uso de EPI's como máscara e luvas, mas constatou-se baixa observação quanto ao uso de artigos descartáveis e esterilizados pelo estabelecimento. Também ocorreu relativa inobservância quanto à utilização de EPC's e de alguns EPI's como gorro, jaleco e óculos de proteção, e quanto ao gerenciamento de resíduos sólidos.

Considera-se que estes resultados possam incentivar a população consumidora de serviços de beleza e estética a buscar e exigir atendimentos dentro das condutas de biossegurança, não aceitando qualquer prática que possa comprometer a sua saúde, deve ainda conscientizar os clientes a valorizar estabelecimentos que estejam de acordo às normas de biossegurança. O profissional da área deve por sua vez, implantar e seguir essas condutas em seu estabelecimento, esclarecendo-as aos seus clientes, aplicando-as e utilizando-as como um diferencial. Para isso, é importante que haja intensificação na difusão das informações e aumento de campanhas, através de folhetos informativos e meios de comunicação, por exemplo, visando educar o público alvo. Vale ainda ressaltar a importância da capacitação do profissional da área, para que os atendimentos sejam cada dia mais seguro e de qualidade.

\section{Referências}

ARDIONS, J. P.; NAVARRO, M. B. M. A.; CARDOSO, T. A. O. Biossegurança e sistemas de informação: a rede e o gerenciamento de risco. Caderno de saúde coletiva, Rio de Janeiro, v. 21, n. 3 , p. $303-308$, Set. 2013.

CARVALHO, C. M. R. S. et al. Aspectos de biossegurança relacionados ao uso de jalecos pelos profissionais de saúde: uma revisão da literatura. Texto contexto-enfim, Florianópolis, v. 18, n. 2, p. $355-360$, Jun. 2009.

BORGES, C.; SANTOS, G. C.; BETTEGA, J. M. P. R. Avaliação da efetividade dos métodos de desinfecção e esterilização em alicates de manicure. 2002. 12 f. Trabalho de Conclusão de Curso (Graduação em Cosmetologia e Estética) - Universidade do Vale do Itajaí, Balneário Camboriú.

CARDOSO, E. N. et al. Adesão dos profissionais às normas de biossegurança aplicadas aos procedimentos de manicure e pedicure em Juazeiro do Norte/ CE. Arquivo de clínica de saúde 
Unipar, Umuarama, v. 18, n. 3, p. 157 -161, Dez.2014.

COSTA, W. M.; FONSECA, M. C. G. A importância do gerenciamento de resíduos hospitalares e seus aspetos positivos para o meio ambiente. Revista Brasileira de Geografia Médica e da Saúde, Belo Horizonte, v.5, n.9, p. 12 - 31, Dez. 2009.

EUFRASIO, B.; SANTOS, C.; NOVOTNY. V. R. O uso de EPI's por profissionais de manicuro e pedicuro. 2011. 19 f. Trabalho de Conclusão de Curso (Graduação em Estética e Cosmetologia) Universidade do Vale do Itajaí, Balneário Piçarras.

FERNANDES, N. I.; SOUSA, A. F. Biossegurança nos estabelecimentos de beleza em Goiânia e região metropolitana. In: Anais do Congresso de Ensino, Pesquisa e Extensão da UEG, CEPE, Goiânia, v. 3, n. 3, Out. 2016.

GARBACCIO, J. L. Conhecimento e adesão às medidas de biossegurança entre manicures e pedicures. 2013. 145f. Tese (Doutorado em Saúde e Enfermagem) - Escola de Enfermagem, Universidade de Minas Gerais, Belo Horizonte.

GARBACCIO, J. L.; OLIVEIRA, A. C. Biossegurança e risco ocupacional: revisão integrativa. Revista Eletrônica de Enfermagem, Belo Horizonte, v. 14, n. 3, p. 702 - 711, Jul/Set. 2012. Disponível em: < https://www.fen.ufg.br/fen_revista/v14/n3/pdf/v14n3a28.pdf > Acessado em: 06 Mar. 2017.

GARCIA, D; MOSER, D. K.; BETTEGA, J. M. P.R. Biossegurança nos salões de beleza de Balneário Camboriú - Santa Catarina. 2007. 27 f. Trabalho de Conclusão de Curso (Graduação em Cosmetologia e Estética) - Universidade do Vale do Itajaí, Balneário Camboriú.

GARCIA, K. A. P.; BENTO, C. F.; COSTA, F. K. Riscos ocupacionais de uma amostra dos profissionais da beleza do município de Goiânia. Revista visão acadêmica, Goiânia, p. 102 - 115, Nov. 2012.

GARCIA, L. P; RAMOS, B. G. Z. Gerenciamento dos resíduos de serviços de saúde: uma questão de biossegurança. Caderno de Saúde Pública, Rio de Janeiro, v. 20, n. 3, p. 744 - 752, Jun. 2004. LOVO, F.G. Biossegurança aplicada para a área da maquiagem. $2011.30 \mathrm{f}$. Trabalho de Conclusão de Curso (Tecnólogo em Gestão de Beleza) - Universidade Luterana do Brasil, Canoas.

KUHN, C.; RENE, M. Percepção das manicures e pedicures frente às hepatites $\mathbf{B}$ e $\mathbf{C}$ e seus métodos de prevenção em salões de beleza na região metropolitana de Curitiba. 2012. $19 \mathrm{f}$. Trabalho de Conclusão de Curso (Tecnólogo em Estética e Imagem Pessoal) - Universidade Tuiuti do Paraná, Paraná.

MELLO, J. Biossegurança e Estética. Revista Científica INA, Blumenau, v. 3, n. 3, p. 5 - 45, Mar. 2011. Disponível em: < http://www.inainstituto.com.br/img_editor/revista.pdf > Acessado em: 19 Mar. 2017.

PINTO, C.; ABREU, D.; GALLAS, J. C.; Análise da percepção dos consumidores em relação à qualidade de atendimento: pesquisado em laboratório no sul de SC. 2008. 21 f. Trabalho de 
Conclusão de Curso (Graduação em Estética e Cosmetologia) - Universidade do Vale do Itajaí, Santa Catarina.

QUEIROZ, M. L. S.; MEJIA, D. Biossegurança nas clínicas de estética e salões de beleza. 2015. 16 f. Trabalho de Conclusão de Curso (Pós - Graduação em Estética e Cosmetologia) - Faculdade Sul Americana, Goiânia.

SOBRINHO, H. M. R. et al. Avaliação do conhecimento e práticas de biossegurança em uma amostra de profissionais da beleza de Goiânia - Goiás. Revista do Instituto de Ciência da Saúde, Goiânia, v. 32, n. 4, p. 343 - 352, Out/Dez. 2014.

SOUZA, N. M. M.; MARCHI, P.; BETTEGA, J. M. P. R. Percepção dos Consumidores de Serviços de Beleza em Relação às Normas de Biossegurança Utilizados em Estabelecimentos de Beleza em Itajaí/SC. 2007. 21 f. Trabalho de Conclusão de Curso (Graduação em Cosmetologia e Estética) - Universidade do Vale do Itajaí, Balneário Camboriú.

VIEIRA, D. C. G. Conhecimento e comportamento de mulheres universitárias sobre hepatites B e C em salões de beleza. 2013. 20 f. Trabalho de Conclusão de Curso (Graduação em Enfermagem) - Faculdade de Ciência da Educação e Saúde, Brasília.

WARMELING, G.; MOREIRA, N.; BETTEGA, J. M. P. R. Implantação de um plano de gerenciamento de resíduos em um centro de beleza em Joinville SC. 2008. $21 \mathrm{f}$. Trabalho de Conclusão de Curso (Graduação em Estética e Cosmetologia) - Universidade do Vale do Itajaí, Santa Catarina. 